Short Note

\title{
Assessing the Relationship between Presidential Rhetorical Simplicity and Unilateral Action
}

\author{
Christopher Olds \\ Department of Political Science, University of Central Florida, Orlando, FL 32816, USA; E-Mail: chris@chrisolds.com
}

Submitted: 27 April 2015 | In Revised Form: 14 June 2015 | Accepted: 27 July 2015 |

Published: 2 September 2015

\begin{abstract}
Research from Shogan (2007) and Lim (2008) on the executive branch proposes that the American presidency has adopted an anti-intellectual approach to leadership, such that there is a concerted rejection of thoughtful political discourse from the president. This has been reflected by what appears to be a relative decline in both the linguistic and substantive complexity of presidential rhetoric. Shogan's (2007) work, while focused on examining whether Republicans are more apt to employ anti-intellectual leadership than Democrats, raises an additional topic worthy of empirical examination: the potential relationship between anti-intellectual leadership and unilateral action from the president. If anti-intellectual leadership is a defiant form of leadership that opts to publicly demonstrate the rejection of external expertise, the usage of anti-intellectual rhetoric from the president might be able to predict the usage of unilateral action. On the other hand, anti-intellectual rhetoric might be used as a straightforward and quick means to explain unilateral action, such that change in the level of unilateral action can predict the usage of simplistic rhetoric. Unfortunately, no one has yet to empirically test whether rhetorical simplicity predicts unilateral action, unilateral action predicts rhetorical simplicity, or there is a multi-directional relationship present. This project makes an initial attempt to remedy this gap in the literature. The project contrasts the monthly average simplicity level of the presidential weekly public address with the monthly number of executive orders emanating from the executive branch, using information spanning between February 1993 and May 2015. The initial findings from the vector autoregression and moving average representation analyses suggest that prior change in rhetorical simplicity predicts the usage of executive orders, and that an increase in rhetorical simplicity helps produce an increase in the number of executive orders offered by the president.
\end{abstract}

\section{Keywords}

anti-intellectualism; Flesch readability; political communication; presidential rhetoric; rhetorical simplicity; unilateral action

\section{Issue}

This short note is part of a regular issue of Politics and Governance, edited by Professor Andrej J. Zwitter (University of Groningen, The Netherlands) and Professor Amelia Hadfield (Canterbury Christ Church University, UK).

(C) 2015 by the author; licensee Cogitatio (Lisbon, Portugal). This article is licensed under a Creative Commons Attribution 4.0 International License (CC BY).

\section{Introduction}

Presidents use public remarks in an attempt to shape the makeup of the country's policy agenda (Kernell, 2007). Public remarks from the executive branch have the potential to influence the outlook citizens have on prominent issue areas (Wood, 2007). When making public remarks, presidents and their speechwriters make intentional decisions about the style of language used that is perceived to be most likely to resonate with the public (Tulis, 1987). One stylistic aspect relates to the complexity of language used by the president (Lim, 2008). In making public remarks that are simplistic in terms of linguistic qualities and substantive depth, presidents could be attempting to make messages from the executive branch more accessible to the general public. By simplifying rhetoric though, there is the possibility that presidential administrations are us- 
ing anti-intellectual discourse that abhors the "needlessly complex processes and products of the intellect," which include activities like theorizing, critical thinking, and examination (Lim, 2008, p. 21).

A president that uses an anti-intellectual style in their rhetorical leadership could be attempting, according to Shogan (2007), to avoid coming across as elitist. Shogan (2007) believes Republicans use antiintellectualism as a form of populism. While antiintellectual leadership can stem from individual attitudes and personal experiences, Shogan (2007) makes clear that anti-intellectual leadership can be a strategic choice made by administrations about the leadership style that is most likely to resonate with the public ( $p$. 295). Given this, Shogan believes that all political elites can be placed along an intellectual/anti-intellectual continuum. This continuum though is dynamic, meaning that the choice to employ anti-intellectual techniques is subject to change. In the words of Shogan (2007, p. 296), "it is overly simplistic to think of presidents as either 'intellectuals' or 'anti-intellectuals.'”

While Shogan's (2007) discussion is centered on the topic of whether Republicans are more likely to adopt an anti-intellectual policy discourse than Democrats in efforts to avoid the personal image characterization often associated with intellectuals of being arrogant and smug, her work also raises an interesting question about whether anti-intellectual techniques are related to unilateral action. Although not fully fleshed out, Shogan's discussion raises various interpretations of how anti-intellectual policy discourse relates to unilateral action. Shogan (2007, p. 296) initially says antiintellectual leadership is a "defiant leadership stancea forceful demonstration of independence. Implicitly, anti-intellectualism conveys the message that the president is in charge and that he answers to no one." Operating under this view, one might think that an increase in anti-intellectual rhetoric from the president will predict an increase in unilateral action from the executive branch. The reason is that anti-intellectual policy discourse can be a means to signal that the president will not engage in a policy debate with others in the political environment. The president through their rhetoric is making clear that they do not find the need to participate in a deliberative exchange, and instead will opt for executive independence on a variety of policy matters. Shogan believes anti-intellectuals will "often advertise their disparagement" of intellectual life (p. 296). One means of doing this is by marginalizing policy details and denigrating policy experts in public remarks before exerting executive independence through unilateral action.

On the other hand, Shogan's discussion can also be interpreted in a way that would lead to the prediction that an increase in specific forms of unilateral action from the executive branch results in an increase in rhetorical simplicity. Using Shogan's (2007, p. 296) words, if anti-intellectualism "emphasizes simplicity and efficiency, which enables presidents to justify their unilateral actions," presidents might use simplistic political discourse when explaining their previous employment of unilateral policy techniques. Presidents, operating under this interpretation, are making clear that unilateral actions are decisions that are not derived from a thoughtful analytical analysis of incoming information. Instead, the usage of unilateral actions under this alternative perspective is rooted in individual instinct, and is explained on these terms. Shogan's write-up of the anti-intellectualism and unilateral action connection can thus be interpreted in different ways regarding the direction of causation, which raises the need for empirical efforts that attempt to address how these concepts might actually relate to each other.

It is particularly important for scholars to make an effort to examine the possible connection between these concepts given the prominence of unilateral action in the modern American presidency. Unilateral actions are a variety of administrative tools and policy techniques that the president can exercise on their own without the cooperation of either the legislative or judicial branches of government (Mayer, 2009). While there have been prior efforts to predict and describe the occurrence of unilateral action (Howell, 2003; Mayer, 2001; Warber, 2006), no work has yet to explore rhetorical simplicity as a variable that can influence, be influenced by, or displays a multidirectional relationship with the occurrence of unilateral policy action. Since the heightened usage of unilateral actions by presidential administrations elicits questions as to the policymaking role of presidents in a system of separated powers (Moe \& Howell, 1999), it is worthwhile to see whether an anti-intellectual rhetorical style has any connection at all to the level of unilateral actions taken by the president. The purpose then of this research project is to assess whether there is any evidence of a connection between presidential rhetorical simplicity and unilateral action. The two alternative research hypotheses that are evaluated as an initial empirical attempt at this area of study are as follows:

Hypothesis 1: Prior change in the level of presidential rhetorical simplicity positively predicts an increase in executive orders.

Hypothesis 2: Prior change in the level of executive orders positively predicts an increase in presidential rhetorical simplicity.

\section{Research Design}

Anti-intellectualism is defined as a "resentment and suspicion of the life of the mind and of those who are considered to represent it; and a disposition constantly 
to minimize the value of that life" (Hofstadter, 1963, p. 7). Presidents can adopt an anti-intellectual communications strategy that is linguistically simplistic and substantively simplistic. Lim's (2008) empirical work compares the Flesch readability formula scores of major presidential addresses to linguistically simple texts (e.g. television scripts) and linguistically complex texts (e.g. academic journal articles). In his work, Lim demonstrates that linguistically simplified texts use fewer words that are indicative of intellectual processing. The Flesch readability formula is calculated by the following equation that evaluates any single body of text: 206.835 minus (1.015 times average sentence length) minus (84.6 times average syllables per word). A higher Flesch readability score suggests a greater level of simplicity.

The analyses performed by Lim (2008) indicate presidential remarks with high Flesch readability scores are less likely to use words from the Harvard-IV content analysis dictionary that suggest the expression of things like similarities and differences between concepts, importance and unimportance of concepts, and awareness or unawareness of concepts. Based on this, linguistically simplified text, as measured by the Flesch readability formula, is also an indicator of substantively simplified text. As a result of these findings, this current project will use the Flesch readability formula to assess rhetorical simplicity. The monthly average Flesch readability score of the president's Saturday address to the public is assessed.

The reason for using the Saturday address as an approximation of presidential rhetorical simplicity levels is that it is the only form of presidential remarks to the public that are consistently measurable. Other public remarks, such as press conference responses, or the State of the Union Address, are offered too infrequently to develop a more time-refined indicator of presidential rhetorical simplicity. Additional types of publicly available remarks, such as economic reports or letters to legislators, often contain technical procedural language that is an inherent part of the presidential office. Using the latter type of public remarks would make it difficult to assess the natural communication style the president prefers to employ with the public at any given point in time. As a result, the weekly address is the form of remarks analyzed in this project. The value of the weekly address in gauging the public communications strategy of the president compelled Hart, Childers and Lind (2013) to devote an entire chapter of their book on political tone to this form of public remarks. Given there has been prominent scholarly literature focusing on the weekly address when empirically evaluating political rhetoric, there is no reason to not use this form of presidential communication for the sake of this project.
To make an effort at measuring unilateral action from the president, the number of executive orders released from the president directing federal administrative agencies on policy is measured. Executive orders are the form of unilateral action studied in this initial analysis, given their prominence in terms of academic study on unilateral action (Major, 2014; Mayer \& Price, 2002). As Major (2014, p. 6) notes, executive orders from the president "are the most systematically documented form of direct action." Executive orders also are commonly focused on in debates amongst legal scholars about the legal merits of unilateral action in the executive branch (Branum, 2002; Duncan, 2010). Future projects are encouraged to build upon the initial findings seen here by assessing the potential connection between presidential rhetorical simplicity and other forms of unilateral action that are publicly available (i.e. presidential proclamations, presidential memoranda, and signing statements), as there is not yet consensus in the scholarship to treat each form of unilateral action as similar enough that they can be combined as a total sum. As a result, much like with the rhetorical simplicity measure, the indicator of unilateral action used for this project is only an approximation of the level of unilateral actions offered at any given point in time. The monthly dynamics for presidential rhetorical simplicity and executive orders are presented in Figure 1.

Additional variables that might influence the level of unilateral actions used by the president in public remarks and/or the level of rhetorical simplicity are also accounted for in this project. Variables assessed in various models include the monthly change in Gallup's presidential approval measure, the presence of divided government, presidential honeymoon periods (the initial three full months of a president's first term), and presidential election years (January through November every presidential election year). Indicators for unique presidential administrations that avoid collinearity issues by omitting one administration (Bill Clinton) as a separate indicator are also included. Lastly, indicators used to measure exogenous prominent events that can warrant swift unilateral action from the president and/or change in rhetorical simplicity levels are included (e.g. terrorist attacks, start of major military conflicts, or natural disasters that cause significant damage).

Since this project is interested in determining the extent of the relationship (if any) between variables that potentially have a multi-directional relationship, it is necessary to use specific time series techniques. The first time series approach is vector autoregression, also known as VAR. The second time series approach is moving average representation, which is abbreviated as MAR. 


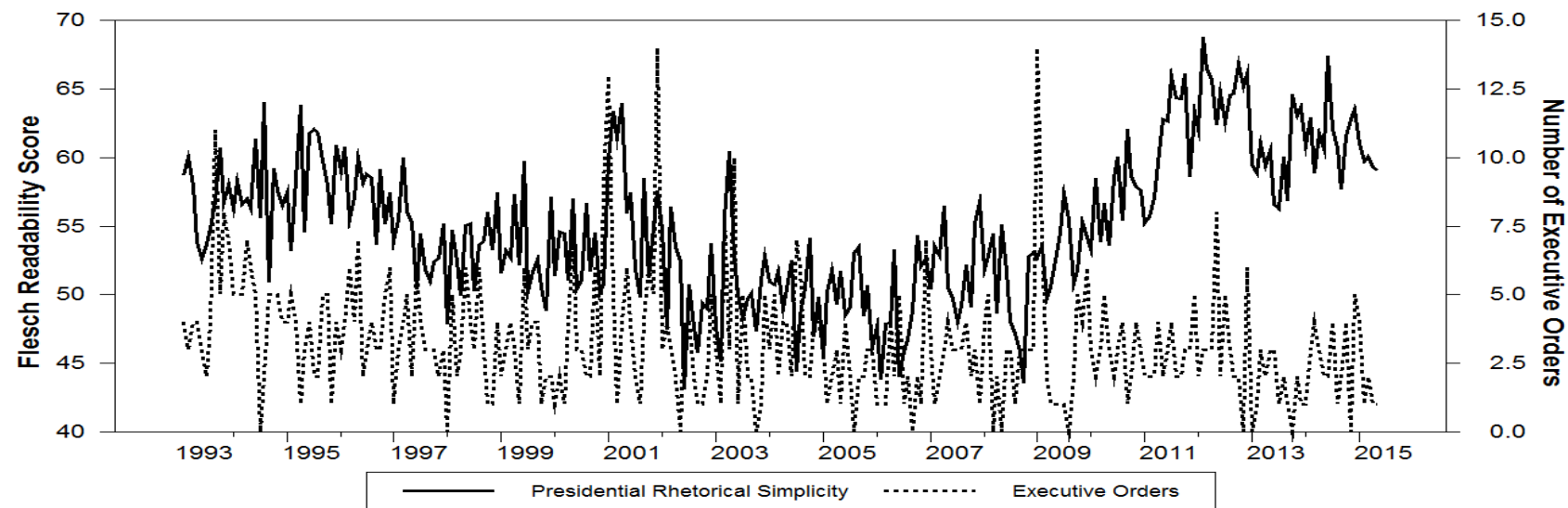

Figure 1. Dynamics of presidential rhetorical simplicity and executive orders, 1993-2015. Note: All information used to create the measures of rhetorical simplicity and unilateral action come from the electronic holdings of the Public Papers of the Presidents hosted by Woolley and Peters (2015). The timeframe analyzed here is February 1993 to May 2015, since the weekly address was reinitiated by President Clinton in February 1993.

The benefit of vector autoregression is that it can assess whether prior change in a variable can predict current values of another variable, all without imposing a theoretical restriction as to which variable is a priori exogenous (Enders, 1996). When conducting a vector autoregression analysis, all the variables are measured in an endogenous variable system. Each variable in this endogenous system is regressed on past values of itself, as well as any other variable in the endogenous system. VAR analysis inherently accounts for history by incorporating multiple lags for each variable in the endogenous system. The inclusion of these lags accounts for the inertial qualities of variables (Sims, 1980), while also accounting for the effects of any variables omitted from the analysis (Eshbaugh-Soha \& Peake, 2011, p. 135). In this project, the endogenous system is comprised of the presidential rhetorical simplicity variable and the executive orders variable.

In vector autoregression, Granger tests are performed in hypothesis tests evaluating the joint significance of coefficients for each variable in each equation analyzed through F-tests (Granger, 1969). What this means is that Granger causality tests performed in vector autoregression can tell us whether the prior values of one variable can together predict the current values of another variable in the system. Such a facet is very important, since the current project intends to assess whether prior levels of presidential rhetorical simplicity can predict the current level of executive orders made, whether the prior level of executive orders can predict the current level of presidential rhetorical simplicity, or a multi-directional relationship exists between the two variables. This is all possible because as Enders (1996, p. 106) asserts, vector autoregression treats all variables within the system as being symmetrical, such that there is no reference made as to which variable is the independent variable in the model, and which variable is the dependent variable in the model. It is also possible using vector autoregression techniques to incorpo- rate the previously mentioned exogenous control variables by modeling each exogenous variable as a potential predictor of current values of any of the two variables within the endogenous system.

While vector autoregression is very helpful in trying to determine the causal direction of the relationship (if any) between variables, Granger causality tests do not reveal whether the direction of any causal relationship between variables in the endogenous system is positive or negative in nature. Vector autoregression is also not capable of giving precise information about the magnitude of the relationship between variables. The reason is that coefficient estimates that are given by hypothesis tests using the Granger approach are plagued by multicollinearity issues due to the incorporation of multiple lags in the endogenous system.

Given these issues, moving average representation is a useful means in which to assess the polarity and magnitude of any relationship in the endogenous system. In a moving average representation analysis, a simulated shock is induced on each variable in the endogenous system, and the response of each variable to this shock is reviewed over an extended period of time (Wood, 2009, pp. 171-172). The MAR procedure then helps indicate whether a variable will increase or decrease in response to a positive shift in another variable that is within the endogenous system studied. The moving average representation procedure also indicates the duration of the shift in one variable following the change induced on another variable. To make sure an intuitive interpretation of the amount of change variables exhibit is possible, all variables in the endogenous system are standardized. That means each variable is rescaled to have a mean of zero and a standard deviation of one. The results of the MAR procedure then will help elaborate how one variable responds over time when another variable is increased by one standard deviation.

Before performing any of these analyses, it is crucial to determine whether each variable in the system is sta- 
tionary. Stationary variables are those that have major statistical properties (e.g. the mean, variance, etc.) that are constant over time. This means stationary variables are random/stochastic with respect to time, and do not exhibit dynamics that move following some deterministic trend. Given that the two variables studied are stationary processes (as indicated in the tests for unit roots detailed in the Appendix), it is possible to employ standard VAR and MAR techniques. A combination of two stationary variables cannot share a common trend across time, which would mean the variables cannot be cointegrated. As a result, it is possible to proceed with using standard VAR and MAR time series techniques.

\section{Research Findings}

The results of the analyses provide initial evidence in support of the view that changes in the simplicity of presidential rhetoric predict change in the level of a major form of unilateral action, executive orders. The results also suggest that an increase in presidential rhetorical simplicity produces a positive (albeit small) shift in the number of executive orders coming from the executive branch. The findings then lend support to the proposal of Hypothesis 1 , and not Hypothesis 2. Rather than anti-intellectual simplistic discourse justifying the usage of unilateral actions, which was one possibility raised by Shogan (2007), anti-intellectual political discourse is a way to "advertise their disparagement" of intellectual life, and use it as a strategic tool to bolster their political authority (p. 296). Presidents can be making a conscious choice to use simplistic rhetoric, such that it is an indicator of the usage of executive orders.

According to the vector autoregression results, prior presidential rhetorical simplicity significantly predicts current levels of executive orders $(p=0.06)$. Past presidential rhetorical simplicity levels Granger-cause the level of executive orders. Presidential rhetoric, at least in this timeframe, predicts the usage of a particular form of unilateral action.

While Shogan (2007) does also raise the possibility that presidents perform unilateral actions, and then explain these actions through simplified discourse, prior change in the level of executive orders does not significantly predict the current level of presidential rhetorical simplicity $(p=0.21)$. For the time period studied, past usage of executive orders does not Granger-cause presidential rhetorical simplicity. There is no indication in the analyses that the usage of executive orders, a prominent form of unilateral action, has a clear direct or indirect effect on presidential rhetorical simplicity. Though prior change in executive orders does not significantly predict presidential rhetorical simplicity, prior change in presidential rhetorical simplicity predicts current levels of presidential rhetorical simplicity $(p=0.00)$. This indicates presidential rhetorical simplicity can be predicted in part by prior levels of pres- idential rhetorical simplicity. The results of the entire vector autoregression analysis are presented in Table 1.

In terms of exogenous controls, there is a significant negative relationship between the Bush administration and rhetorical simplicity (suggesting the complexity of foreign affairs and the domestic economy during this period shaped presidential rhetoric to be less simplistic). There is a positive and significant relationship between the Obama administration and rhetorical simplicity, which could be a reflection of the change in circumstances during the Obama administration, and/or a difference in rhetorical strategy by the Obama administration. The occurrence of some prominent events (the Oklahoma City bombing, the September $11^{\text {th }}$ terrorist attacks, and the start of the Second Iraq War) increased the current level of presidential rhetorical simplicity. Trying to assuage concerns within the public about the ramifications of these particular events could increase executive branch efforts to talk about these events in a straightforward manner.

Although prior presidential rhetorical simplicity does Granger-cause the level of executive orders offered by the president, presidential rhetorical simplicity is not the only variable that helps shape the level of executive orders offered by the president. Like presidential rhetorical simplicity, prior executive order levels predict current executive order values $(p=0.06)$, suggesting that the level of executive orders is determined in part by prior levels of executive orders. In terms of the exogenous controls, presidential approval exhibits a positive relationship with the level of executive orders. A positive change in presidential approval levels might give an administration the sense that they have the political capital with the general public, such that they can take unilateral actions without experiencing a significant backlash.

There is a significant negative relationship between the presence of divided government and the amount of executive orders offered by the executive branch. When there is a difference in party attachment between the President and Congress, employing executive orders might exacerbate partisan tension, which can potentially make presidents more reluctant to use these or other forms of unilateral action. Another significant exogenous variable is the Barack Obama administration. The significant and negative relationship between the Obama administration and the number of executive orders is a reflection of the relatively lower levels of executive orders offered during the Obama administration compared to levels seen at times during administrations that preceded President Obama's. The start of the Second Iraq War was also positively associated with the level of executive orders. It is the only event measured that exhibits a statistically significant association with the level of executive orders. While one might assume that major exogenous events would significantly predict the level of executive orders issued from the executive branch, the 
statistical analyses performed in this project do not offer much support for this proposal.

The moving average representation analysis findings suggest the relationship between presidential rhetorical simplicity and the level of executive orders is positive. In column one of row two of Figure 2, the dynamic response of executive orders to a one standard deviation increase to presidential rhetorical simplicity is displayed. At the contemporaneous point of the one standard deviation shift to presidential rhetorical simplicity, there is a 0.1 standard deviation increase in the level of executive orders from the executive branch.
This increase is significant, as indicated by the $95 \%$ confidence interval being bounded away from the standardized mean of zero.

The level of executive orders returns to being positive and significantly away from the standardized mean following the first month post-shock to presidential rhetorical simplicity. This increase lasts between months two and five, until the decay to the standardized mean begins to be clear around month six. For several months then, there is a positive and small increase in executive orders following a positive shock to presidential rhetorical simplicity.

Table 1. Granger tests for presidential rhetorical simplicity and executive order endogenous system.

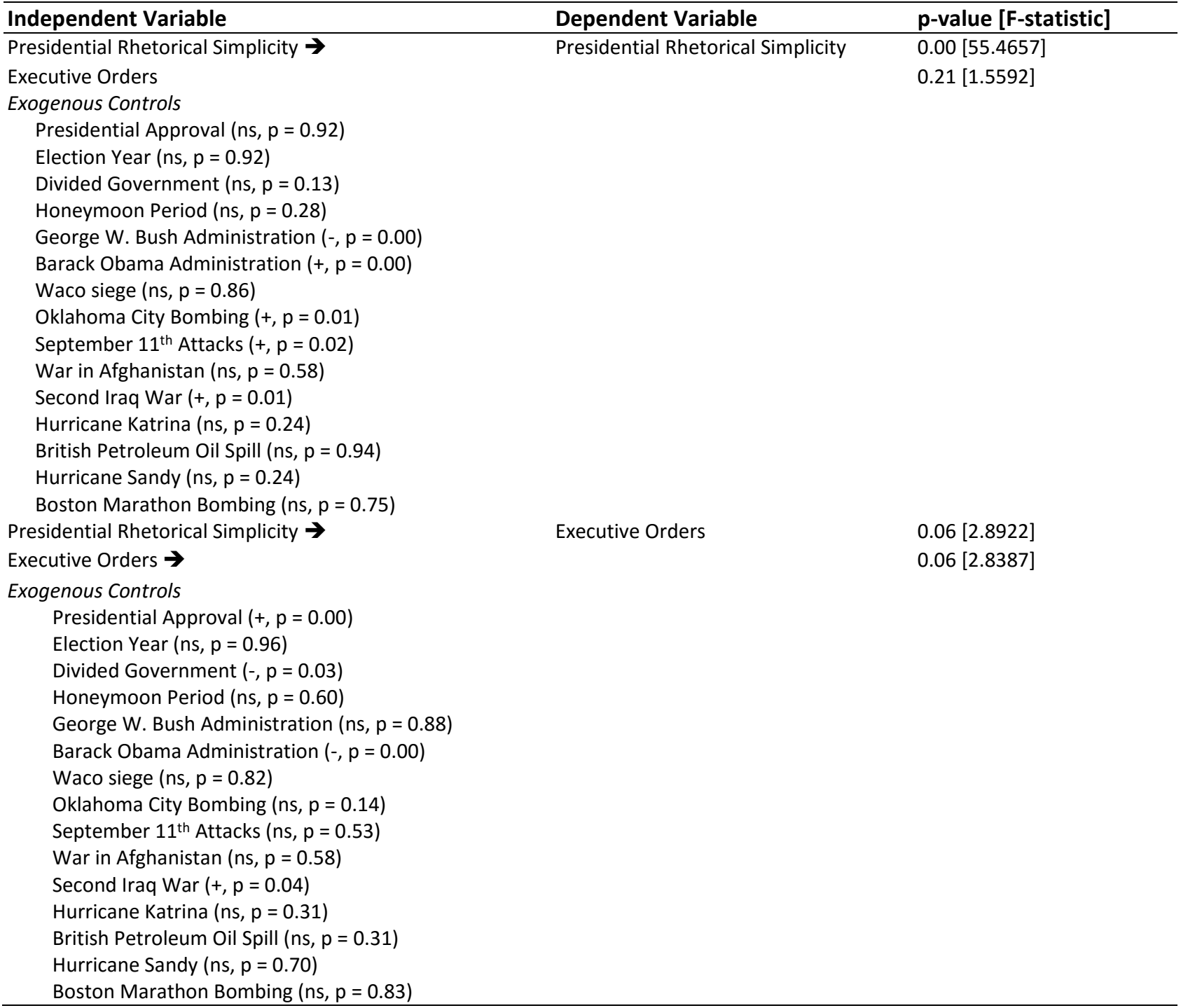

Note: The arrows indicate Granger-causality from the block of coefficients for the independent variable to the dependent variable based on 0.10 significance levels. The $p$-values are from F-tests for the null hypothesis of no Grangercausality. The system includes a deterministic constant. The results of the exogenous controls are based on t-test results using 0.10 significance levels. As seen in presidency research from Eshbaugh-Soha \& Peake (2011), Wood (2007), and Wood (2009), Granger-causality tests often employ 0.10 significance levels, given the analytical procedure and structure of the model being analyzed. A "+" represents a positive significant relationship, a "_" represents a negative significant relationship, and "ns" represents not significant. Each of the independent variables in the system includes two monthly lags to control for the inertia of the variables. Lag length is selected by Bayesian Information Criterion (BIC). VAR estimation with lags performed with information between 04/1993 and 05/2015. 

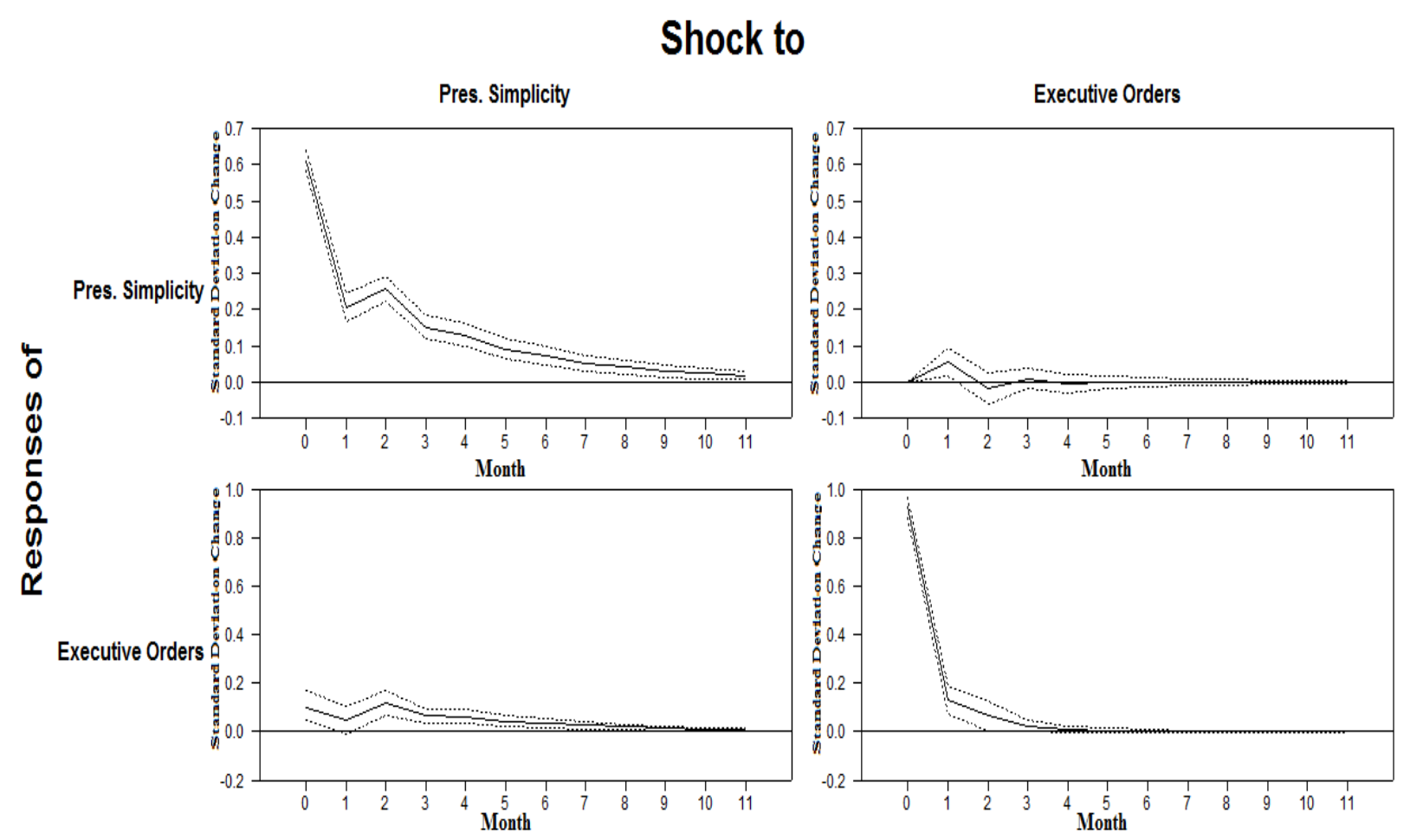

Figure 2. Moving average representation impulse responses for endogenous system. Note: Dashed lines represent $95 \%$ confidence intervals.

Column two of row one demonstrates the response of presidential rhetorical simplicity to a one standard deviation positive shift in executive orders. For no extended period of time is the level of presidential rhetorical simplicity significantly away from the standardized mean of zero. The $95 \%$ confidence interval not being clearly shifted away from the standardized mean for a discernible extended period of time in the MAR analysis reinforces the results seen in the VAR analysis. In the vector autoregression analysis, prior change in executive orders fails to predict current levels in presidential rhetorical simplicity. The moving average representation analysis shows a positive shift in executive orders does not move presidential rhetorical simplicity in a positive or negative direction for any clear duration of time.

It appears that presidents through their rhetoric offer a signal with an increase in simplistic discourse that the usage of executive orders, a prominent and controversial unilateral technique, will occur more frequently. Shogan (2007, p. 296) implies anti-intellectuals come to conclusions based on gut instinct given existing circumstances; pervasive anti-intellectual policy discourse could potentially be taken as a cue that a president at a given point in time believes unilateral action is the most effective option in terms of leadership. The increased usage of simplistic statements to the public can be a possible sign that the president will increasingly adopt the position that unilateral policy tools are necessary, and will execute the usage of unilateral policy tools. Continued study as to whether this result is found with not just executive orders, but other forms of unilateral policy tools, will help to further substantiate that simplistic rhetorical discourse from the president predicts unilateral actions from the executive branch.

\section{Conclusions}

Work on anti-intellectualism in the American presidency by Shogan (2007), while focused on the matter of whether presidents aligned with the Republican Party are more apt to adopt an anti-intellectual leadership approach than presidents aligned with the Democratic Party, also happens to raise an interesting topic worthy of empirical assessment. The topic involves the relationship between anti-intellectual leadership techniques and the usage of unilateral actions. Given this topic was not the crux of the article's discussion or theory, any relationship between anti-intellectual leadership and the usage of unilateral action is arguably open to interpretation of Shogan's brief statements on this topic. In order to address this topic, the current project attempts to assess the relationship between presidential rhetorical simplicity (a clear indicator of an anti-intellectual leadership approach based on Lim (2008) and Shogan's (2007) important work), and the usage of executive orders, a prominent and controversial form of unilateral action.

The time series analyses demonstrate that prior change in presidential rhetorical simplicity levels predicts change in the level of executive orders from the 
executive branch. Prior change in the level of executive orders does not appear to predict change in presidential rhetorical simplicity levels. Presidents appear to make clear by simplifying their policy rhetoric that an increase in executive orders is forthcoming. Antiintellectual leadership is rooted in a variety of aspects like instincts, moral sensibilities, emotional states, and aspects of personal character (Shogan, 2007, p. 295). The dynamic nature of some of these aspects makes it worthwhile to explore the connection between presidential rhetorical simplicity and executive orders using time-refined indicators of each variable. As the very first empirical study attempting to assess the relationship between anti-intellectual leadership techniques and unilateral action, this project will hopefully serve as a contribution to future scholarship by compelling others to attempt to validate the causal direction between the concepts evaluated in the project. Constructing a thorough theoretical framework that can help explain the findings of this exploratory analysis in a way that clarifies why and when a linkage between rhetorical simplicity and unilateral action will be observable can be a significant contribution to the literature on presidential leadership, political communication, and managerial behavior. If anything, this project has hopefully served as an impetus for future theory building and development on establishing an explanatory basis for why rhetorical simplicity could be a signal suggesting acts of executive independence are forthcoming.

Future research should also make an effort to employ various empirical strategies to validate whether the positive relationship observed here between rhetorical simplicity and unilateral action in the American presidency holds. One possibility that immediately stands out is to repeat the approach used in this project and then examine other forms of unilateral action (e.g. signing statements, proclamations, etc.). Whether or not the results seen in this study are observed when analyzing other forms of unilateral action is a fruitful avenue worthy of exploration. If anything, this project hopefully will inspire quantitative scholars of the American presidency to evaluate proposals and claims made by scholarship that explores the executive branch from a more qualitative approach. Scholars of all backgrounds studying the presidency are better served by engaging in an exchange of ideas with everyone else, regardless of methodological training and background.

\section{Acknowledgments}

The author extends words of gratitude to the editorial staff at Cogitatio Press for ensuring a fair and transparent peer review process.

\section{Conflict of Interests}

The author declares no conflict of interests.

\section{References}

Branum, T. L. (2002). President or king-The use and abuse of executive orders in modern-day America. Journal of Legislation, 28, 1-86.

Duncan, J. C. (2010). A critical consideration of executive orders: Glimmerings of autopoiesis in the executive role. Vermont Law Review, 35, 333-411.

Enders, W. (1996). RATS handbook for econometric time series. New York: John Wiley \& Sons.

Eshbaugh-Soha, M., \& Peake, J. S. (2011). Breaking through the noise: Presidential leadership, public opinion, and the news media. Stanford, CA: Stanford University Press.

Granger, C. W. J. (1969). Investigating causal relations by econometric models and cross-spectral models. Econometrica, 37, 424-438.

Hart, R. P., Childers, J. P., \& Lind, C. J. (2013). Political tone: How leaders talk \& why. Chicago: University of Chicago Press.

Hofstadter, R. (1963). Anti-intellectualism in American life. New York: Knopf.

Howell, W. G. (2003). Power without persuasion: The politics of direct presidential action. Princeton, NJ: Princeton University Press.

Kernell, S. (2007). Going public: New strategies of presidential leadership ( $4^{\text {th }}$ ed.). Washington, D.C.: CQ Press.

Lim, E. T. (2008). The anti-intellectual presidency: The decline of presidential rhetoric from George Washington to George W. Bush. Oxford, UK: Oxford University Press.

Major, M. (2014). The unilateral presidency and the news media: The politics of framing executive power. New York: Palgrave Macmillan.

Mayer, K. R. (2001). With the stroke of a pen: Executive orders and presidential power. Princeton, NJ: Princeton University Press.

Mayer, K. R. (2009). Going alone: The presidential power of unilateral action. In G. C. Edwards III \& W. G. Howell (Eds.), The Oxford handbook of the American presidency (pp. 427-454). Oxford, UK: Oxford University Press.

Mayer, K. R., \& Price, K. (2002). Unilateral presidential powers: Significant executive orders, 1949-99. Presidential Studies Quarterly, 32, 367-386.

Moe, T. M., \& Howell, W. G. (1999). The presidential power of unilateral action. Journal of Law, Economics, and Organizations, 15, 132-179.

Shogan, C. (2007). Anti-intellectualism in the American presidency. Perspectives on Politics, 5, 295-303.

Sims, C. A. (1980). Macroeconomics and reality. Econometrica, 48, 1-48.

Tulis, J. K. (1987). The rhetorical presidency. Princeton, NJ: Princeton University Press.

Warber, A. L. (2006). Executive orders and the modern presidency: Legislating from the oval office. Boul- 
der, CO: Lynne Rienner Publishers.

Wood, B. D. (2007). The politics of economic leadership.

Princeton, NJ: Princeton University Press.

Wood, B. D. (2009). The myth of presidential represen- tation. Cambridge, UK: Cambridge University Press. Woolley, J., \& Peters, G. (2015). The American presidency project [Database]. Retrieved from http://www.presidency.ucsb.edu

\section{About the Author}

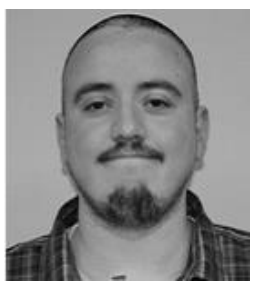

\section{Dr. Christopher Olds}

Christopher Olds is a Visiting Assistant Professor at the University of Central Florida. Dr. Olds earned his doctorate in Political Science at Texas A\&M University. His approach to empirical political science embraces the usage of interdisciplinary inquiry. The major area of emphasis in his current research is assessing the causes and consequences of stylistic changes in presidential rhetoric. He has published research in Congress \& the Presidency, White House Studies, and other outlets that integrate work from various academic fields. 


\section{Appendix}

Table A1. Tests for the Presence of Unit Root in Endogenous Variables

\begin{tabular}{|c|c|c|c|}
\hline $\begin{array}{l}\text { Dickey-Fuller Unit Root } \\
\text { Test for Presidential } \\
\text { Rhetorical Simplicity } \\
\text { Series }\end{array}$ & $\begin{array}{l}\text { Phillips-Perron Unit Root } \\
\text { Test for Presidential } \\
\text { Rhetorical Simplicity } \\
\text { Series }\end{array}$ & $\begin{array}{l}\text { Dickey-Fuller Unit Root } \\
\text { Test for Executive Order } \\
\text { Series }\end{array}$ & $\begin{array}{l}\text { Phillips-Perron Unit Root } \\
\text { Test for Executive Order } \\
\text { Series }\end{array}$ \\
\hline Lag Number: 0 & Lag Number: 0 & Lag Number: 0 & Lag Number: 0 \\
\hline Sig. Level Crit. Value & Sig. Level Crit. Value & Sig. Level Crit. Value & Sig. Level Crit. Value \\
\hline $1 \%(* *)-3.45629$ & $1 \%(* *)-3.456292$ & $1 \%(* *)-3.45629$ & $1 \%(* *)-3.456292$ \\
\hline $5 \%(*)-2.87243$ & $5 \%(*)-2.872433$ & $5 \%(*)-2.87243$ & $5 \%(*)-2.872433$ \\
\hline $10 \%-2.57253$ & $10 \%-2.572528$ & $10 \%-2.57253$ & $10 \%-2.572528$ \\
\hline t-statistic $-6.62001^{* *}$ & t-statistic $-6.64495^{* *}$ & t-statistic $-13.2919 * *$ & t-statistic $-13.3419 * *$ \\
\hline Observations 268 & Observations 267 & Observations 268 & Observations 267 \\
\hline Lag Number: 1 & Lag Number: 1 & Lag Number: 1 & Lag Number: 1 \\
\hline Sig. Level Crit. Value & Sig. Level Crit. Value & Sig. Level Crit. Value & Sig. Level Crit. Value \\
\hline $1 \%(* *)-3.45638$ & $1 \%(* *)-3.456292$ & $1 \%(* *)-3.45638$ & $1 \%(* *)-3.456292$ \\
\hline $5 \%(*)-2.87247$ & $5 \%(*)-2.872433$ & $5 \%(*)-2.87247$ & $5 \%(*)-2.872433$ \\
\hline $10 \%-2.57255$ & $10 \%-2.572528$ & $10 \%-2.57255$ & $10 \%-2.572528$ \\
\hline t-statistic $-4.01272 * *$ & t-statistic $-5.92868 * *$ & t-statistic $-9.44134^{* *}$ & t-statistic $-13.3215^{* *}$ \\
\hline Observations 267 & Observations 267 & Observations 267 & Observations 267 \\
\hline Lag Number: 2 & Lag Number: 2 & Lag Number: 2 & Lag Number: 2 \\
\hline Sig. Level Crit. Value & Sig. Level Crit. Value & Sig. Level Crit. Value & Sig. Level Crit. Value \\
\hline $1 \%(* *)-3.45647$ & $1 \%(* *)-3.456292$ & $1 \%(* *)-3.45647$ & $1 \%(* *)-3.456292$ \\
\hline $5 \%\left({ }^{*}\right)-2.87251$ & $5 \%(*)-2.872433$ & $5 \%(*)-2.87251$ & $5 \%(*)-2.872433$ \\
\hline $10 \%-2.57257$ & $10 \%-2.572528$ & $10 \%-2.57257$ & $10 \%-2.572528$ \\
\hline t-Statistic -3.39108* & t-statistic $-6.02522^{* *}$ & t-statistic $-7.87874^{* *}$ & t-statistic $-13.3776^{* *}$ \\
\hline Observations 266 & Observations 267 & Observations 266 & Observations 267 \\
\hline Lag Number: 3 & Lag Number: 3 & Lag Number: 3 & Lag Number: 3 \\
\hline Sig. Level Crit. Value & Sig. Level Crit. Value & Sig. Level Crit. Value & Sig. Level Crit. Value \\
\hline $1 \%(* *)-3.45655$ & $1 \%(* *)-3.456292$ & $1 \%(* *)-3.45655$ & $1 \%(* *)-3.456292$ \\
\hline $5 \%\left({ }^{*}\right)-2.87255$ & $5 \%(*)-2.872433$ & $5 \%(*)-2.87255$ & $5 \%(*)-2.872433$ \\
\hline $10 \%-2.57259$ & $10 \%-2.572528$ & $10 \%-2.57259$ & $10 \%-2.572528$ \\
\hline t-statistic $-2.88041^{*}$ & t-statistic $-6.12141^{* *}$ & t-statistic $-7.05507^{* *}$ & t-statistic $-13.4357^{* *}$ \\
\hline Observations 265 & Observations 267 & Observations 265 & Observations 267 \\
\hline
\end{tabular}

Note: Null hypothesis in all unit root tests above is that the analyzed series contains a unit root, while the alternative hypothesis is that the analyzed series is produced by a stationary process. 